This item was submitted to Loughborough's Institutional Repository (https://dspace.lboro.ac.uk/) by the author and is made available under the following Creative Commons Licence conditions.

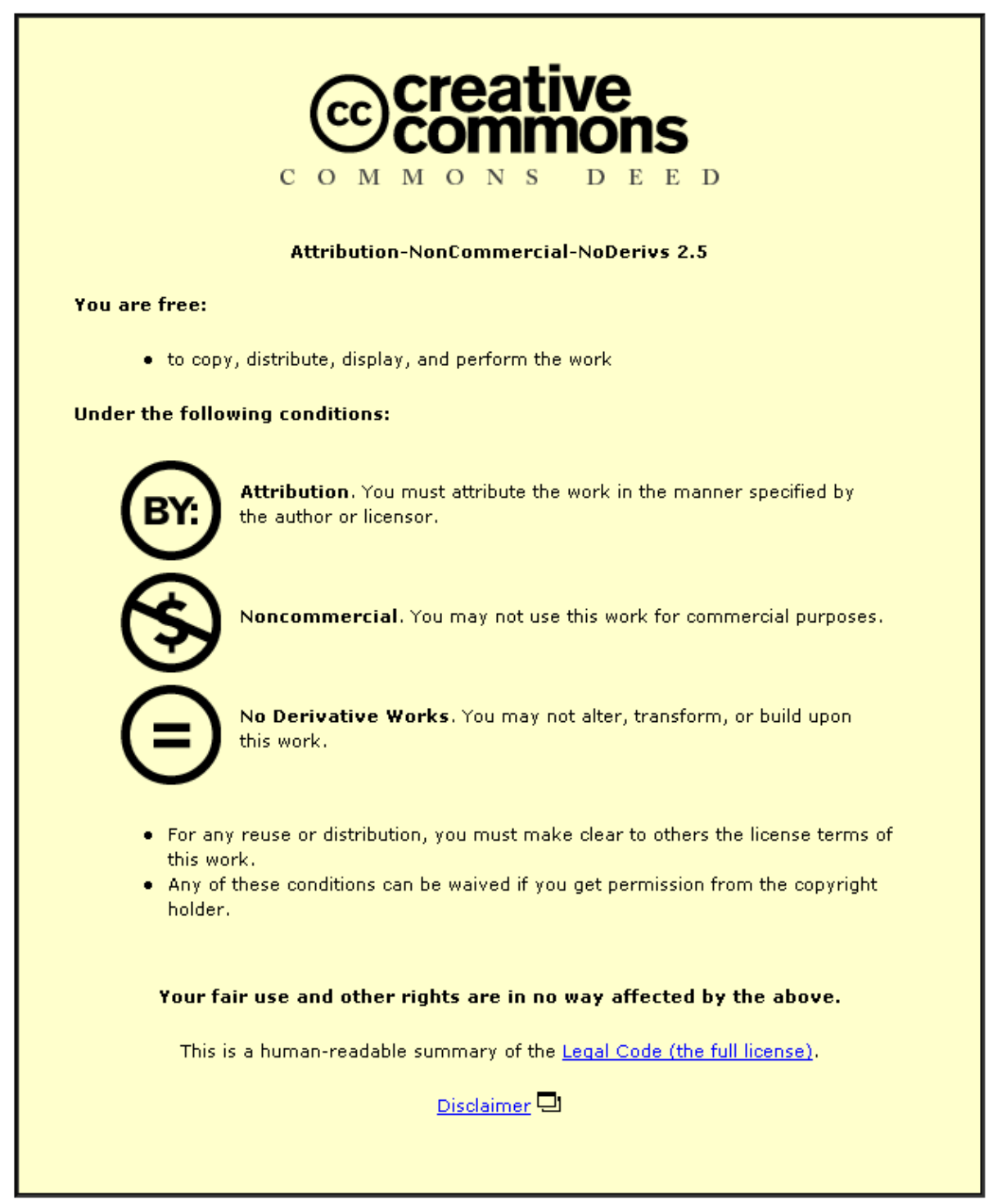

For the full text of this licence, please go to: http://creativecommons.org/licenses/by-nc-nd/2.5/ 


\title{
Modelling the effects of combustion and turbulence on near-wall temperature gradients in the cylinders of spark ignition engines
}

\author{
R J Jenkin, E H James and W M Malalasekera \\ Department of Mechanical Engineering, Loughborough University, Leicestershire
}

\begin{abstract}
An existing quasi-dimensional engine cycle model has been modified to enable accurate prediction of the near-wall temperature field in the burned and unburned gases. This has been achieved by dividing the cylinder into a number of discrete masses, each of which has a unique state. These discrete masses are assumed to remain stacked in layers adjacent to the cylinder walls in both the unburned gas and in the discrete segments generated during the sequential burning process. A $k-\varepsilon$ turbulence model has been incorporated into the engine cycle simulation, providing information on the nature of the instantaneous in-cylinder turbulence for input to a fractal flame model to depict the flame propagation process. When this approach is applied to the prediction of the flame propagation rate, excellent comparison is afforded between simulated and measured pressure-crank angle diagrams. Further validation is provided by comparison of near-wall temperature predictions with measured ones and the essential features of the observed boundary layer behaviour are reproduced.
\end{abstract}

Keywords: combustion, turbulence, temperature gradients, spark-ignition engines, cylinder, flame propagation

$\begin{array}{lll}\text { NOTATION } & & N \\ A & \text { flame front area } & P \\ B_{m}, B_{2} & \text { laminar burning velocity expression } & Q \\ & \text { constants } & r \\ C & \text { specific heat capacity at constant pres- } & R \\ & \text { sure } & R e \\ C_{\varepsilon 1}, C_{\varepsilon 2}, C_{\varepsilon 3}, C_{\mu} & \text { turbulence model constants } & t \\ D_{3} & \text { fractal dimension } & T \\ E & \text { energy } & u \\ f & \text { diluent mass fraction } & u^{\prime} \\ G_{\rho k} & \text { turbulence source terms } & u_{\mathrm{eff}}^{\prime} \\ h & \text { specific enthalpy } & \boldsymbol{u} \\ H & \text { clearance height } & U \\ k & \text { turbulence kinetic energy } & v \\ k_{0} & \text { initial turbulence kinetic energy } & V \\ l_{\mathrm{i}} & \text { integral length scale } & x \\ l_{\mathrm{K}} & \text { Kolmogorov length scale } & \\ l_{\max } & \text { maximum cut-off length } & \delta \\ l_{\min } & \text { minimum cut-off length } & \delta_{\mathrm{u}} \\ m & \text { mass } & \\ n & \text { number of elements } & \Delta Q \\ & & \varepsilon \\ & & \varepsilon_{0} \\ \text { The MS was received on 12 August 1997 and was accepted for publication } & \lambda \\ \text { on 15 January 1998. } & & \mu\end{array}$

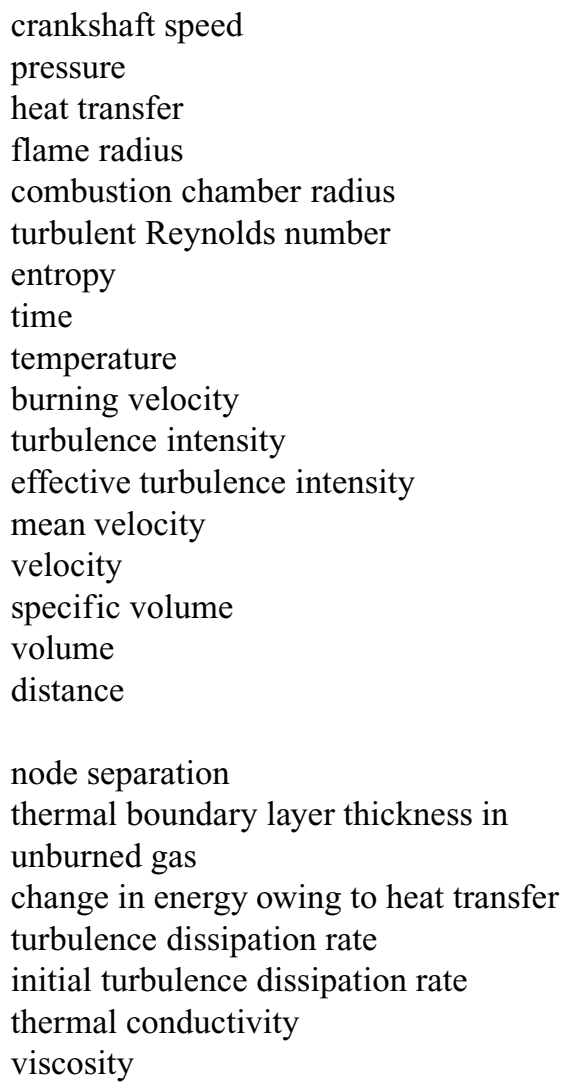




$\begin{array}{ll}\xi & \text { turbulent eddy thermal conductivity } \\ \rho & \text { density } \\ \sigma & \text { Prandtl number } \\ \tau_{i j} & \text { Reynolds stress tensor } \\ \tau_{\mathrm{w}} & \text { wall shear stress } \\ \phi & \text { equivalence ratio } \\ \phi_{m} & \text { reference equivalence ratio } \\ \psi & \text { turbulent eddy viscosity } \\ \omega & \text { swirl angular velocity }\end{array}$

\section{Subscripts}

$\begin{array}{ll}0 & \text { initial state } \\ 1 & \text { state } 1 \\ 2 & \text { state } 2 \\ \mathrm{~b} & \text { burned } \\ e & \text { referring to conserved property of node } \\ & \text { east of } p \\ \mathrm{f} & \text { enflamed } \\ j & \text { corresponding to } j \text { th estimate in itera- } \\ & \text { tive solution } \\ 1 & \text { laminar } \\ p & \text { referring to conserved property of node } \\ \mathrm{t} & \text { under consideration } \\ \mathrm{u} & \text { turbulent } \\ w & \text { unburned } \\ & \text { referring to conserved property of node } \\ & \text { west of } p\end{array}$

\section{INTRODUCTION}

Computerized models of engine cycles are well established in the analysis of the processes occurring in the cylinders of spark ignition engines. Such models are either predictive, semi-predictive or analytical. Analytical models $[\mathbf{1 , 2}]$ use thermodynamic relationships to compute the combustion rate and gas temperatures from experimental cylinder pressure data. Semi-predictive models use empirically derived, algebraic expressions to account for the mass burning rate while totally predictive models compute the rate of flame propagation using fundamental expressions accounting for the combustion chemistry and the interactions of the flame with the in-cylinder turbulence. Predictive models are useful in as much as they can, once validated at certain operational points, provide information on the processes occurring in the cylinder beyond that which can be observed experimentally. They also enable the parametric investigation of engine design criteria that might otherwise be impractical if prototype engines had to be manufactured for the purpose. The majority of such simulations are employed to investigate the phenomena affecting engine efficiency, pollutant formation and abnormal combustion.

Many of the processes contributing to abnormal combustion are highly temperature dependent, as shown by
Griffiths et al. [3] who investigated the influence of the end-gas temperature on the delay prior to auto-ignition in a rapid compression machine. They noted that the ignition delay periods and the amplitude of the pressure oscillations associated with knock were significantly affected by the unburned gas temperature. Several experimental studies have concluded that auto-igniting exothermic centres (capable of developing into knock-inducing combustion events) [4-6] are most likely to occur in the near-wall regions. In this context also, Cheng et al. [7] identified fuel storage in such regions (particularly piston ring crevices) and the absorption and desorption of fuel in oil layers on the combustion chamber surfaces as major sources of unburned hydrocarbon emissions. Both mechanisms result in the release of unreacted or partially reacted fuel into the burned gases after the passage of the flame. A significant proportion of these hydrocarbons are converted into combustion products by post-flame oxidation reactions which are highly dependent on the temperature levels in such near-wall regions $[\mathbf{8}, \mathbf{9}]$.

An accurate picture of the temperature field at these locations is desirable in order to forward the understanding of the events leading to knocking combustion and the phenomena responsible for the production of unburned hydrocarbon emissions. Lydford-Pike and Heywood [10] used schlieren photography to observe significant density gradients near to the cylinder walls of a square, transparent research engine, implying temperature gradients in these regions. Lucht et al. [11] used coherent anti-RamanStokes scattering (CARS) and Farrell [12] used speckle interferometry to resolve the near-wall temperature gradients in optical access research engines. Temperature gradients were observed adjacent to the cylinder walls in both studies. The near-wall temperature gradients measured by Lucht et al. [11] in a 'motored' engine exhibited considerable differences when the intake system was altered to produce different amounts of swirl. Temperature profiles measured in a 'fired' engine also showed differences compared with those obtained in the motored case, suggesting that combustion influenced the near-wall temperature profiles. These effects have not been experimentally investigated beyond these limited cases owing to the complexity of making such measurements. To this end, a computerized engine cycle model with the ability to predict the influence of combustion, in-cylinder flows and engine operating conditions on the near-wall temperature gradients has been developed.

In this paper the thermodynamic engine cycle model is presented along with details pertaining to the development of the submodels accounting for the in-cylinder flow and turbulent burning velocity. Validation is provided by comparing predicted pressure-crank angle diagrams, turbulence intensities and near-wall temperature gradients with those measured in a single cylinder research engine over a range of operating conditions [11, 13]. Finally, the model's limitations and potential uses as a development tool are described. 


\section{REVIEW OF PREVIOUS WORK}

Computational fluid dynamics (CFD) codes would appear to be the logical choice for the simulation of spatial variations in the conserved properties near the cylinder walls in engines. However, the scale of the thermal boundary layer region relative to the overall domain (the cylinder) poses several problems. Numerical simulation of the thermal boundary layer requires a large number of data points near to the walls in order to resolve the steep gradients in the region. Solution accuracy and stability limit the degree to which the nodes can be weighted towards the walls, necessitating dense computational meshes throughout the entire domain. This results in mathematical problems requiring large amounts of computational time and memory, making their solution impractical with most currently available computer hardware. Jennings and Morel [14] overcame this by patching a fine one-dimensional CFD mesh in the boundary layer region to a conventional, multidimensional mesh in the bulk of the cylinder. They were able to demonstrate the effects of the cylinder wall temperature on the near-wall temperature gradients and the flame quench distance [15]. There is some doubt as to the validity of their $k-\varepsilon$ turbulence model near to the walls in light of the anisotropy of turbulence in these regions [16] and the limited applicability of $k-\varepsilon$ theory in such flows [17]. Also, there is no validation provided for their predictions.

Several simplified analytical techniques have been used to account for near-wall temperature gradients. Pan and Sheppard [18] arbitrarily specified end-gas temperature gradients as input into their two-dimensional code for the analysis of the modes of auto-ignition. Min and Cheng [19] computed the thermal boundary layer temperature profile using expressions for the dimensionless temperature profile empirically derived from the measurements of Lucht et al. [11] and the thermal boundary layer thicknesses measured by Lydford-Pike and Heywood [10]. Lavoie and Blumberg [20] accounted for the thermal boundary layer in a quasidimensional model by the use of a linear temperature profile.

\section{ENGINE CYCLE MODELLING}

The mathematical equations for thermodynamic models are derived by invoking the principles of the conservation of energy and mass. CFD models consider the conservation of mass, momentum, species and enthalpy on a control volume basis [21], resulting in considerably larger mathematical problems when compared with thermodynamic models owing to the increased number of unknowns and the complex solution techniques required. The advantage of the significantly reduced computational times associated with thermodynamic models is accompanied with the disadvantage that they cannot account for spatially dependent phenomena such as gradient diffusion or describe scalar fields such as temperature. However, simple geometric features can be accounted for in a quasi-dimensional manner by assuming dimensional features such as a spherical flame front. When this type of analysis is employed, the cylinder gas is often divided into two or more zones (generally representative of the burned and unburned gases). Each zone is considered as a separate thermodynamic system with unique conserved properties. In this context, quasi-dimensional models can represent spatial variations in the conserved properties of the cylinder gases.

As discussed earlier, the temperature field has a significant effect on many in-cylinder processes. In order to improve the accuracy with which such phenomena can be modelled, a quasi-dimensional engine simulation has been developed in which the near-wall temperature gradients are accounted for. An existing model [22-24] has been extended in such a manner that the cylinder contents can be divided into many mass elements. The in-cylinder gas is divided into four zones: three adjacent to the cylinder head, liner and piston crown and a homogeneous core region (Fig. 1).

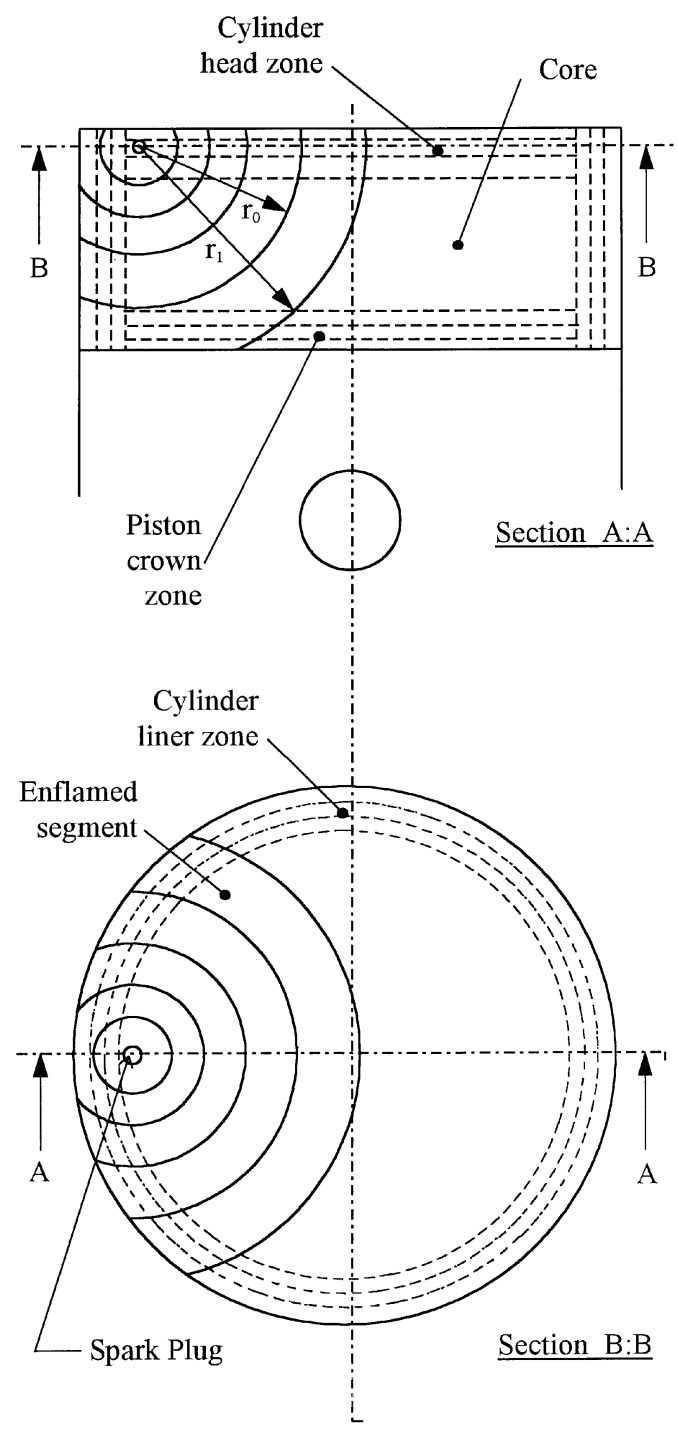

Fig. 1 Mass elements in a typical cylinder 
Each of the zones adjacent to the walls are then divided further into thin 'slices' which are assumed to remain 'stacked' in layers adjacent to the combustion chamber surfaces. After ignition, a spherical flame front is assumed to propagate from a specified point representative of the centre of the spark plug electrode gap. The unburned gas entrained by the propagating flame (e.g. see Fig. 1) is from $r_{0}$ to $r_{1}$, representative of the flame locations at the beginning and end of a calculation step. The unburned mass consumed during this time interval creates a new burned segment.

The instantaneous cylinder pressure and the temperature of each mass is computed progressively throughout the compression, combustion and expansion phases of the engine cycle (usually every degree of crank angle rotation). The mathematical techniques are based on those developed by Phillips and Orman [25]. In order to make the solution mathematically viable, the combustion process at each progressive stage is divided into two substeps:

1. A combustion substep where an element of mass is transferred from the unburned to the burned state. The process is allowed to occur adiabatically and at constant overall volume (i.e. no piston motion).

2. A piston motion and heat transfer substep where the energy exchange due to the gas/wall interface heat transfer and the work interactions between the gas and the moving piston are accounted for.

These assumptions are viable in these circumstances because the iterative techniques used yield a solution for the values of the conserved properties at the end of each process. The point values defining the state of the cylinder contents at a particular time in the cycle can be accurately arrived at by any chosen path.

The equations for the first substep are cast using formulations for the conservation of energy and volume according to

$$
E_{1}=E_{0}
$$

and

$$
V_{1}=V_{0}
$$

where

$$
E_{1}=\sum_{i=1, n_{\mathrm{b}}} m_{\mathrm{b}_{i}} e_{\mathrm{b}_{i}}+\sum_{i=1, n_{\mathrm{u}}} m_{\mathrm{u}_{i}} e_{\mathrm{u}_{i}}+m_{\mathrm{f}} e_{\mathrm{f}}
$$

and

$$
V_{1}=\sum_{i=1, n_{\mathrm{b}}} m_{\mathrm{b}_{i}} v_{\mathrm{b}_{i}}+\sum_{i=1, n_{\mathrm{u}}} m_{\mathrm{u}_{i}} v_{\mathrm{u}_{i}}+m_{\mathrm{f}} v_{\mathrm{f}}
$$

Also, for all but the enflamed mass which is experiencing a change of state, the entropy can be assumed to be constant throughout the process and the equations

$$
S_{\mathrm{u}_{i_{1}}}=S_{\mathrm{u}_{i_{0}}} \quad \text { for } i=1, n_{\mathrm{u}}
$$

and

$$
S_{\mathrm{b}_{i_{1}}}=S_{\mathrm{b}_{i_{0}}} \quad \text { for } i=1, n_{\mathrm{b}}
$$

apply. All properties at state 0 are known from the end of the previous calculation step or, in the case of the first combustion interval, the end of the compression stroke. Thus, equations (1) and (2) are used to establish the values of $E_{1}$ and $V_{1}$ in equations (3) and (4) respectively. The specific internal energy and volume of each mass element and also the corresponding entropy values are functions of temperature and pressure. Equations (3) and (4) are expanded to form first-order Taylor series involving the partial derivatives of internal energy and specific volume with respect to pressure and the relative burnt or unburned gas temperature. Equations (5) and (6) are similarly expanded to yield a number of Taylor series involving the relevant temperature and pressure derivatives of entropy. The resulting equations are rearranged and solved simultaneously as part of an iterative solution to yield the burnt and unburned gas temperatures and uniform cylinder pressure at the end of combustion substep one.

A unique solution for this substep exists when there is only one enflamed volume. However, with the newly developed model several masses must be transferred from the unburned to the burned state simultaneously as the flame advances from $r_{0}$ to $r_{1}$ (see Fig. 1). In order to maintain the mathematical viability of the solution, they are accounted for one at a time. As such, all but one of these masses are considered to be unburned gas, the exception being the currently enflamed mass element. An intermediate solution is then found by performing the calculations described above on this basis. The intermediate solution provides the initial conditions for the calculations pertaining to the transfer of the next element to the burned state. This process continues until all the enflamed masses have been accounted for (Fig. 2).

The cylinder volume at the end of the second substep is easily obtained from the engine geometry and the crankshaft position. It can also be written in terms of the individual mass elements at the end of this substep, i.e.

$$
V_{2}=\sum_{i=1, n_{\mathrm{b}}} m_{\mathrm{b}_{i}} v_{\mathrm{b}_{i}}+\sum_{i=1, n_{\mathrm{u}}} m_{\mathrm{u}_{i}} v_{\mathrm{u}_{i}}
$$

where $n_{\mathrm{b}}$ includes all the masses burned up to the end of the current time interval. The cylinder pressure and gas temperatures at the end of the first substep are used as initial conditions for the second substep calculation (Fig. 2). Also, the entropy of each mass element at the end of the second substep can be found by employing the equations

$$
S_{i_{2}}=S_{i_{1}}+\frac{2 \Delta Q_{i}}{T_{i_{2}}+T_{i_{1}}} \quad \text { for } i=1, n
$$

to each burnt and unburned gas mass element. 


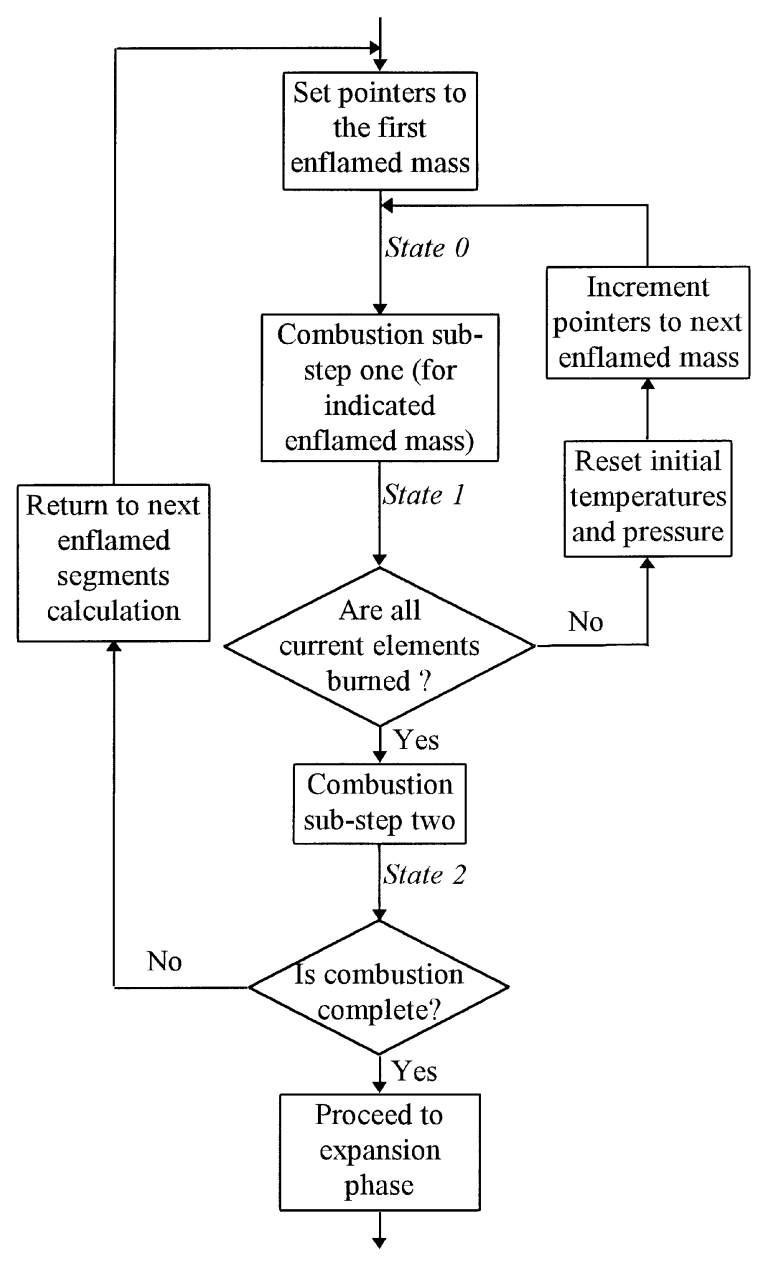

Fig. 2 Combustion process (flow diagram)

Again, equations (7) and (8) can be expressed as firstorder Taylor series and solved in the same way as those for substep one. The process shown in Fig. 2 is repeated until all the unburned mass is consumed, at which point combustion is terminated and the program proceeds to the expansion stroke calculations.

During the compression and expansion processes, there is heat transfer and piston motion but no combustion. Both processes are modelled in a similar way to combustion substep two except that during compression $n_{\mathrm{b}}=0$ and throughout expansion $n_{\mathrm{u}}=1$. An unburned element (of exceptionally small mass in this situation) is maintained throughout the expansion stroke in the mathematical routines to generalize the procedures so as to account for any gas escaping combustion in future work involving hydrocarbon emissions prediction.

\section{PREDICTING HEAT TRANSFER AND NEAR- WALL TEMPERATURE GRADIENTS}

It is necessary to quantify the heat transfer from each mass element in order to calculate the entropy changes due to heat transfer. This is achieved by coupling the thermodynamic engine simulation with a one-dimensional CFD mesh for the solution of the conservation of enthalpy equation. Enthalpy is used as the conserved property because this is a recognized method of accounting for energy in CFD computations. Additionally, when energy is accounted for in this form, changes in the conserved property owing to the influences of external work are expressed as the time derivative of pressure only, thus significantly simplifying the solution process.

In the absence of pressure gradients, viscous heating and source terms, the conservation of enthalpy equation can be written as

$$
\frac{\partial(\rho h)}{\partial t}+\nabla \cdot(\rho h \boldsymbol{u})=\frac{\mathrm{d} P}{\mathrm{~d} t}+\nabla \cdot(k \nabla T)
$$

The predominant near-wall temperature gradients have been observed to be normal to the cylinder wall [10-12] so that the derivatives parallel to the wall can be neglected. Also, the convective transport of enthalpy is split into components owing to the fluctuating and time averaged velocities, the latter of which are assumed to be negligible. Finally, the Bossinesq relationship is used to account for turbulent eddy transport via the inclusion of a coefficient for the turbulent eddy transport of enthalpy, $\xi$, in the diffusion term. On this basis, equation (9) is rearranged to become

$$
\frac{\partial \overline{(\rho h)}}{\partial t}=\frac{\partial}{\partial x}\left[(\lambda+\xi) \frac{\partial \bar{T}}{\partial x}\right]+\frac{\mathrm{d} P}{\mathrm{~d} t}
$$

This is discretized by integrating over a control volume and a finite time [24]. The gas density is assumed to be constant over the duration of a small time step, allowing the onedimensional mesh to be superimposed on the system of masses for each zone (Fig. 3) excepting those which are

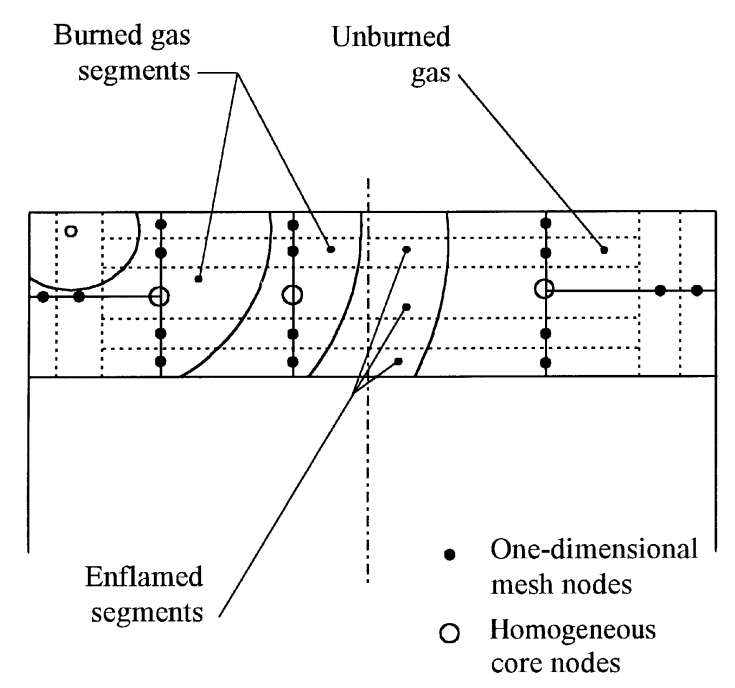

Fig. 3 Superimposition of one-dimensional grids and mass elements 
currently enflamed, as the constant density assumption is not valid for the rapidly expanding gas in the flame front. Term $\mathrm{d} P / \mathrm{d} t$ in equation (10) is estimated using the intermediate state 2 pressure, $P_{2 j}$, from the iterative thermodynamic solution according to the equation $\mathrm{d} P / \mathrm{d} t=$ $\left(P_{2 j}-P_{0}\right) / \Delta t$. The state 0 temperatures and the intermediate value of $\mathrm{d} P / \mathrm{d} t$ provide the input for the onedimensional conservation of enthalpy model which implicitly predicts the new temperatures for use as the next estimates in the iterative solution of the thermodynamic model (Fig. 4). The equation

$$
\Delta Q_{i} \approx m_{i}\left[\bar{C}_{i}\left(T_{i}-T_{0 i}\right)-\left(P-P_{0}\right) \bar{v}_{i}\right] \quad \text { for } i=1, n
$$

is used to compute the heat transfer for each mass element excepting those which are currently burning. Changes in entropy for each mass element owing to heat transfer are then evaluated by equations (8).

Fourier's law was discretized to yield the expression

$$
\dot{q}_{w}^{\prime \prime}=-(\xi+\lambda)_{w, p 1}\left(\frac{T_{p 1}-T_{w}}{\delta_{w, p 1}}\right)
$$

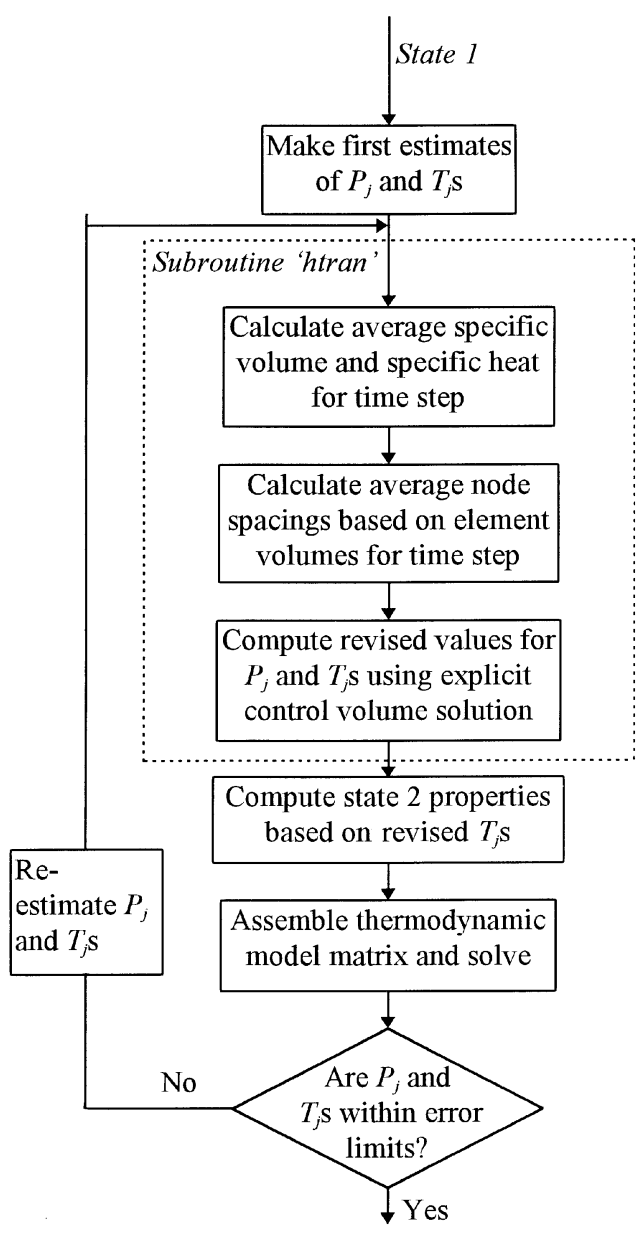

Fig. 4 Combustion substep 2 with heat transfer which is used to evaluate the gas/wall interface heat flux. Further details of these techniques can be found in reference [21].

\section{IN-CYLINDER FLOW MODELLING}

It has been recognized for many years that the rate of flame propagation in spark ignition engines is strongly affected by the in-cylinder flow. Lancaster [26], in a summary of several experimental works, came to the commonly accepted conclusion that the turbulent component of the flow was the important factor. Therefore, a model embodying the important aspects of the flow field influencing the rate of flame propagation only needs to consider the characteristics of the turbulence commonly found in commercial and experimental spark ignition engines. Such a model has been developed for application in this work.

Rask [27] studied the in-cylinder turbulence during the intake and the early part of the compression stroke and noted anisotropic behaviour at such times. However, turbulence has been noted to become approximately homogeneous and isotropic in both swirling [28-31] and tumbling flows [32-34] as top dead centre (TDC) is approached. From this, it can be concluded that heterogeneous, anisotropic turbulence is produced during the intake process which, through the effects of turbulent dissipation and diffusion, becomes isotropic and homogeneous as the piston approaches TDC.

The $k-\varepsilon$ turbulence model can be applied to model isotropic turbulence. Transport equations for the turbulence kinetic energy, $k$, and the turbulent eddy dissipation rate, $\varepsilon$, generally take the form

$$
\begin{aligned}
\frac{\partial(\rho k)}{\partial t}+\nabla \cdot(\rho U k)= & \nabla \cdot\left(\frac{\psi}{\sigma_{k}} \nabla k\right)-\rho \varepsilon+G_{\rho k} \\
\frac{\partial(\rho \varepsilon)}{\partial t}+\nabla \cdot(\rho U \varepsilon)= & \nabla \cdot\left(\frac{\psi}{\sigma_{\varepsilon}} \nabla \varepsilon\right)+C_{\varepsilon 1} G_{\rho k} \frac{\varepsilon}{k} \\
& -C_{\varepsilon 2} \rho \frac{\varepsilon^{2}}{k}+C_{\varepsilon 3} \rho \varepsilon \nabla U
\end{aligned}
$$

This turbulence model has been used in 'lumped mass' form in several previous works [35-38]. The instantaneous values of turbulence kinetic energy and the turbulent eddy dissipation rate averaged over the entire combustion chamber volume are evaluated on the assumption that the incylinder turbulence is approximately homogeneous. In such circumstances there are no spatial gradients of $k$ or $\varepsilon$ and the convective and diffusive terms in equations (13) and (14) reduce to zero, leaving the equations

$$
\begin{aligned}
& \frac{\partial(\rho k)}{\partial t}=G_{\rho k}-\rho \varepsilon \\
& \frac{\partial(\rho \varepsilon)}{\partial t}=C_{\varepsilon 1} G_{\rho k} \frac{\varepsilon}{k}-C_{\varepsilon 2} \rho \frac{\varepsilon^{2}}{k}
\end{aligned}
$$


The source term for the turbulence kinetic energy, $G_{\rho k}$, is equal to the product of the Reynolds stresses and the velocity gradient so that

$$
G_{\rho k}=-\rho \overline{u_{i}^{\prime} u_{j}^{\prime}} \cdot \frac{\mathrm{d} U_{i}}{\mathrm{~d} x_{j}}
$$

From the continuity equation, $\mathrm{d} U_{i} / \mathrm{d} x_{i}=-(1 / \rho)(\mathrm{d} \rho / \mathrm{d} t)$ and, for the case of isotropic turbulence, $u^{\prime 2}=2 k / 3$. This can be substituted in equation (17) for the special case where $i=j$ to give

$$
G_{\rho k}=\frac{2}{3} k \frac{\mathrm{d} \rho}{\mathrm{d} t} \quad \text { for } i=j
$$

Equation (18) is incorporated into a source term expression applicable for all values of $i$ and $j$ to give

$$
G_{\rho k}=\frac{2}{3} k \frac{\mathrm{d} \rho}{\mathrm{d} t}+\left(\tau_{i j}-\rho \frac{2}{3} k \delta_{i j}\right) \frac{\mathrm{d} U_{i}}{\mathrm{~d} x_{j}}
$$

The second bracketed term maintains the overall equality of the expression. If the bracketed terms are expanded, in the case of isotropic turbulence all the terms in the leading diagonal of the tensor become zero and equation (19) reduces to

$$
G_{\rho k}=\frac{2}{3} k \frac{\mathrm{d} \rho}{\mathrm{d} t}+\tau_{i j} \cdot \frac{\mathrm{d} U_{i}}{\mathrm{~d} x_{j}} \quad \text { for } i \neq j
$$

where the first and second terms on the right-hand side are the production of turbulent kinetic energy by dilation effects and shear respectively.

Several researchers have noted that the mean velocity field approaches solid body rotation with swirling flows in pancake-shaped combustion chambers [39], the characteristics of which remain until combustion begins [40]. In the case of solid body rotation there is no shear within the fluid. Therefore, turbulence is produced only as a result of flow dilation in the bulk gases. However, high velocity gradients are apparent at the cylinder walls $[\mathbf{1 6}, \mathbf{4 1}-\mathbf{4 2}]$. The wall shear stress has been calculated using friction coefficient theory [43] and the boundary layer velocity profile is assumed to increase linearly from zero adjacent to the wall (no slip assumption) to the tangential velocity of the swirling flow at the outer limit of the momentum boundary layer. Values for the boundary layer thickness have been estimated from measurements found in the literature $[\mathbf{1 6}, \mathbf{4 2}]$. The Reynolds stresses in the near-wall region are assumed to be approximately equal to the wall shear stress so that

$$
G_{\rho k(\text { shear })}=\tau_{\mathrm{w}} \frac{\omega R}{\delta_{\mathrm{u}}}
$$

An initial value for the swirl angular velocity, $\omega$, is provided as empirical input. Thereafter, $\omega$ is assumed to decrease by 40 per cent during the compression process in accordance with measurements $[\mathbf{2 8}, \mathbf{3 0}]$. Turbulence generated in the near-wall region is assumed quickly to diffuse throughout the entire cylinder, thus acting like a point source. Initial conditions for the turbulence properties are specified at bottom dead centre using the generally accepted conventions for jet type flows [21]. The initial turbulence kinetic energy, $k_{0}$, is specified as 15 per cent of the bulk flow kinetic energy of the incoming gas. The initial turbulence dissipation rate, $\varepsilon_{0}$, is computed using the equation $\varepsilon_{0}=k_{0}^{3 / 2} / l$, where $l$ is 0.035 times the valve lift. Solution is afforded by the simultaneous integration of equations (15) and (16).

The eddy viscosity, $\psi$, is calculated from the conserved turbulence properties using the expression

$$
\psi=C_{\mu} \rho \frac{k^{3 / 2}}{\varepsilon}
$$

and the ratio of the turbulent and laminar conductivities, $\xi / \lambda$, is computed according to

$$
\frac{\xi}{\lambda}=\frac{\psi}{\sigma} \frac{\sigma_{\mathrm{t}}}{\mu}
$$

for use in the numerical solution of equation (10). Thermal conductivity, $\lambda$, is evaluated using a polynomial curve fit to values from tables for air. Ratio $\xi / \lambda$ is assumed to decrease linearly between the outer edge of the momentum boundary layer and the viscous sublayer throughout which $\xi$ is assumed to be zero [44]. The instantaneous turbulence intensity is computed from the instantaneous turbulence kinetic energy using the expression

$$
u^{\prime}=\frac{2}{3}(k)^{1 / 2}
$$

derived from the definition of the turbulence kinetic energy. Predicted turbulence intensities for motored operation are compared with those measured in the optical access research engine at Sandia [13] in Fig. 5. Table 1 summarizes the engine specification. The general trend of increasing turbulence intensity towards TDC before a rapid decay early in the expansion stroke is predicted at all engine speeds. Differences in the magnitudes of the predicted and measured values are apparent. This is likely to be due to discrepancies between the flow field in the research engine and the idealized swirling case assumed by the model. The engine has small valves mounted in the side of the combustion chamber. As a result, a highly turbulent flow field with very little swirl and a small amount of tumble is established during the intake process. Engine speeds and associated empirical input are listed in Table 2. The parameter labelled 'turbulence generation' specifies the initial swirl ratio in the idealized flow model. The model is not an accurate representation of the flow in this 

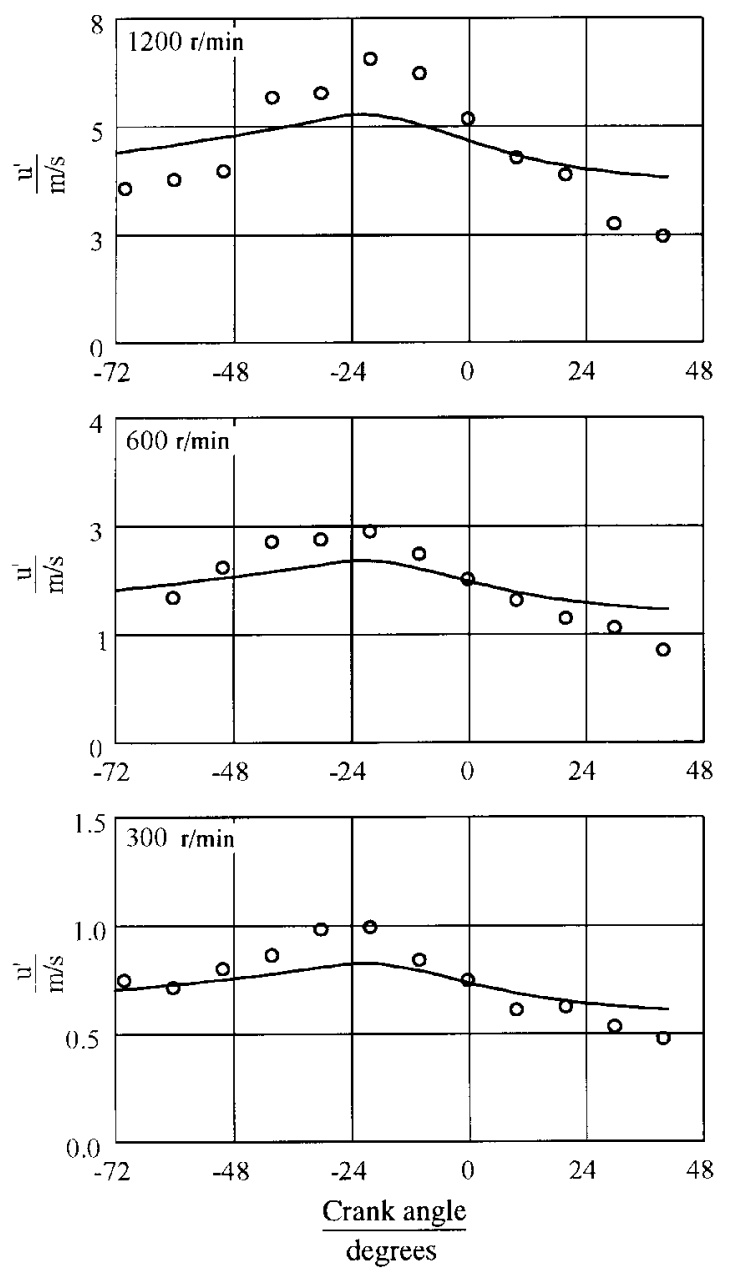

- Expcrimental — Predicted

Fig. 5 Predicted and measured [13] turbulence intensities at three engine speeds

Table 1 Sandia optical access research engine specification [13]

\begin{tabular}{ll}
\hline Combustion chamber & Pancake \\
Compression ratio & 5.4 \\
Bore $(\mathrm{cm})$ & 7.62 \\
Stroke $(\mathrm{cm})$ & 8.255 \\
Conrod length $(\mathrm{cm})$ & 20.3 \\
Fuel & Propane \\
Crevice volume $\left(\mathrm{cm}^{3}\right)$ & 3 \\
Wall temperature $(\mathrm{K})$ & 440 \\
Throttle & Wide open \\
\hline
\end{tabular}

Table 2 Empirically based input for simulations of motored engine [13]

\begin{tabular}{llll}
\hline & \multicolumn{3}{c}{ Engine speed (r/min) } \\
\cline { 2 - 4 } & 300 & 600 & 1200 \\
\hline Turbulence generation & 2.75 & 3.75 & 4.75 \\
Temperature at IVC (K) & 350 & 350 & 350 \\
Pressure at IVC (bar) & 1.2 & 1.2 & 1.2 \\
\hline
\end{tabular}

engine and it was necessary to use values in excess of those preferred for a low-swirl engine in order to account for the unusually intense turbulence generated by this engine during the induction process. However, even taking into account such discrepancies in operating conditions, the turbulence model reproduces turbulence intensities with a maximum error of 17 per cent. This is acceptable in view of the fact that the measurements are ensemble averages and are subsequently liable to be in excess of the real instantaneous values as they include fluctuations in the mean velocity as a result of the cyclic variations [29].

\section{RATE OF FLAME PROPAGATION}

Flames in spark ignition engines are generally accepted to be in the wrinkled laminar regime [45]. Under such conditions, the turbulent burning velocity can be obtained by the expression presented by Gouldin [46] which can be written as

$$
u_{\mathrm{t}}=u_{1} \frac{A_{\mathrm{t}}}{A_{1}}
$$

For homogeneous, isotropic turbulence, as is predominantly the case in the unburned gas at the time of combustion, the cascading length scales can be considered as self-similar and (statistically) homogeneous. Given these facts, Gouldin [46] observed that fractal analysis could be used to quantify the perturbation of the flame sheet by the in-cylinder turbulence, enabling evaluation of the surface area of the wrinkled flame. A power law scaling between the measurement size and the measurement scale used results via

$$
u_{\mathrm{t}}=u_{1}\left(\frac{l_{\max }}{l_{\min }}\right)^{\left(D_{3}-2\right)}
$$

where $D_{3}$ is the fractal dimension, $l_{\max }$ and $l_{\min }$ are the maximum and minimum wrinkling scales respectively, and $u_{1}$ is the laminar burning velocity (for propane in this case) computed with the expressions obtained by Metghalchi and Keck [47], which can be summarized as

$$
u_{1}=u_{10}\left(\frac{T_{\mathrm{u}}}{T_{0}}\right)^{\alpha}\left(\frac{P}{P_{0}}\right)^{\beta}(1-2.1 f)
$$

where

$$
\begin{aligned}
& u_{10}=B_{m}+B_{2}\left(\phi-\phi_{m}\right)^{2} \\
& \alpha=2.18-0.8(\phi-1) \\
& \beta=-0.16+0.22(\phi-1)
\end{aligned}
$$

and $T_{0}=298 \mathrm{~K}$ and $P_{0}=1 \mathrm{~atm}$. Mantzaras [45] has shown that below $u^{\prime} / u_{1}=15$ there is an inner limit to the 
length scales that exhibit fractal behaviour. Fractal flame models (FFMs) have been used successfully in engines even though $u^{\prime} / u_{1}$ is often less than this critical limit because the scales of turbulence smaller than those exhibiting fractal behaviour do not contribute to the convolution of the flame surface as they are smoothed out by the laminar flame propagation [46]. Length $l_{\min }$ has been observed to be 1.3-5.8 times the Kolmogorov length scale $l_{\mathrm{K}}[48,49]$. In the light of this, the minimum length scale is specified as $3 l_{\mathrm{K}}$, where $l_{\mathrm{K}}$ is computed from the turbulence dissipation rate and the gas kinematic viscosity using the expression

$$
l_{\mathrm{K}}=\left(\frac{v^{3}}{\varepsilon}\right)^{1 / 4}
$$

Length $l_{\max }$ has been observed to be several times larger than the integral length scale $l_{\mathrm{i}}[\mathbf{5 0}, \mathbf{5 1}]$ and is limited by the flame size until the flame becomes constrained by the combustion chamber surfaces, at which point the maximum wrinkling scale is restricted by the cylinder geometry. The piecewise expression

$$
l_{\max }= \begin{cases}r_{\mathrm{f}}, & 0<r_{\mathrm{f}}<H \\ H, & H<r_{\mathrm{f}}\end{cases}
$$

(where $l_{\max }$ is limited by the clearance height, $H$ ) is used here. Chin et al. [49] conducted a comprehensive investigation into the sensitivity of predicted flame speed ratios (FSRs) to errors in the calculation of $l_{\max }$ and $l_{\min }$ and concluded that they only had a small influence on the FSR owing to the power term in equation (26).

Zhao et al. [52] suggested the following equation for the fractal dimension based on the turbulent Reynolds number:

$$
D_{3}=2\left(\frac{200}{R e+200}\right)+2.35\left(\frac{R e}{R e+200}\right)
$$

Preliminary investigations into the applicability of equation (30) within the context of the current model indicated that, when this expression was used, the FSR was significantly overpredicted when turbulence levels realistic to the engine under simulation were employed. North and Santavicca [48] developed the heuristic expression

$$
D_{3}=2\left(\frac{u_{1}}{u^{\prime}+u_{1}}\right)+2.35\left(\frac{u^{\prime}}{u^{\prime}+u_{1}}\right)
$$

for the fractal dimension based on the ratio of the turbulence intensity and the laminar burning velocity, $u^{\prime} / u_{1}$. This approach accounts for the competing effects of the wrinkling of the flame surface by the turbulence and the smoothing effects of the laminar flame propagation and when employed here more realistic values for the FSR were achieved. Fractal dimensions have been shown to vary with the ratio $u^{\prime} / u_{1}$ from 2 for laminar flames to $2.37 \pm 3$ per cent for highly turbulent flames $[45,48,50,53]$. In light of this, the modified expression of Chin et al. [49]

$$
D_{3}=2\left(\frac{u_{1}}{u^{\prime}+u_{1}}\right)+2.37\left(\frac{u^{\prime}}{u^{\prime}+u_{1}}\right)
$$

is used throughout this work. The value for the instantaneous turbulence intensity is computed from the turbulence kinetic energy via equation (24). However, when the flame is small, it only 'senses' turbulent fluctuations with length scales smaller than its dimensions. Santavicca et al. [54] and Harweg and Maly [55] used frequency analysis of the turbulent spectrum to account for this, while Wu et al. [56] used energy cascade arguments to yield the expression

$$
\varepsilon=\frac{u^{\prime 3}}{l_{\mathrm{i}}}=\frac{u_{\mathrm{eff}}^{\prime 3}}{r_{\mathrm{f}}}
$$

which is applied here in the form

$$
u_{\text {eff }}^{\prime}=\left(\frac{r_{\mathrm{f}}}{\varepsilon}\right)^{1 / 3}, \quad 0<r_{\mathrm{f}}<l_{\mathrm{i}}
$$

to compute the effective turbulence intensity experienced by small flames.

Experimental [57] and theoretical [58] studies of the propagation of premixed flames in enclosures have shown that non-spherical flame shapes result when the flame is close to, or in contact with, the confining surfaces. Spherical flames have the smallest surface/volume ratio geometrically possible and any deviation from this shape results in an increase in the surface/volume ratio, yielding a higher rate of mass entrainment by the propagating flame. In order to account for this, a method based on the work of Barr and Witze [58] and similar to that used by Matthews et al. [59] is employed. Piecewise expressions accounting for the increase in the rate of entrainment of the unburned gas as the flame approaches the piston

$$
\left(\frac{u_{\mathrm{t}}}{u_{\mathrm{l}}}\right)_{\mathrm{eff}}= \begin{cases}1.05\left(\frac{u_{\mathrm{t}}}{u_{\mathrm{l}}}\right), & 0.9 H<r_{\mathrm{f}}<H \\ 1.10\left(\frac{u_{\mathrm{t}}}{u_{\mathrm{l}}}\right), & H<r_{\mathrm{f}}\end{cases}
$$

have been developed and are employed throughout this work. As the flame approaches the cylinder walls, it has been observed to slow down. This is attributed to the combined effects of reduced laminar burning velocities in the cooler unburned gases in the thermal boundary layer and the dampening of the turbulence intensities and maximum wrinkling scales by the presence of the solid wall. The effects of the unburned gas temperature on the laminar burning velocity are accounted for in the expression for $u_{1}$. In the absence of comprehensive data pertaining to the effect of the proximity of the wall on the flame wrinkling scales and turbulence dissipation rate, it was not possible to 
develop models to account for these phenomena. However, Foster and Witze [42] have noted an approximately linear decay in the component of the turbulence intensity normal to the cylinder wall as the wall is approached. In light of this, a crude model has been developed in which the turbulence intensity has been assumed to vary linearly in the near-wall region according to

$$
u_{\text {eff }}^{\prime}=u^{\prime} \frac{r_{\text {max }}-r_{\mathrm{f}}}{x_{\text {crit }}}, \quad 0<\left(r_{\max }-r_{\mathrm{f}}\right)<x_{\text {crit }}
$$

where $u^{\prime}$ is the value obtained from equation (24) and $x_{\text {crit }}$ is the critical distance from the wall, below which the flame speed is affected by its proximity.

Table 3 summarizes typical flame kernel radii data measured $0.5 \mathrm{~ms}$ after ignition. The data of Shen et al. [60] and Boulouchos et al. [61] was taken directly from plots of flame radii versus time. Equivalent kernel radii were computed from Harweg and Maly's kernel volume data [55] by assuming spherical flame propagation. A 'delay period' is specified as input to the engine cycle model to account for the time taken in crank angle degrees (CAD) for the formation of a kernel of mass $5 \times 10^{-5} \mathrm{~g}$ corresponding to a flame radius of approximately $2.5 \mathrm{~mm}$. This is comparable with the values summarized in Table 3 for the propane fuelled cases. These delay periods are subject to cyclic variability [60]. Kumar et al. [62] statistically analysed flame photographs of the early flame propagation over 20-30 consecutive cycles and noted a standard deviation in the flame radius after a period of 3.2 CAD for a low-swirl case at $1200 \mathrm{r} / \mathrm{min}$. In the light of this, the delay period has been adjusted in some simulations. The methods for computing the FSR detailed above are then employed to compute the instantaneous burning velocity at the beginning of each calculation step.

\section{MODEL VALIDATION}

Figure 6 shows comparisons between simulated pressurecrank angle diagrams and those measured in the Sandia

Table 3 Approximate flame radii $0.5 \mathrm{~ms}$ after ignition

\begin{tabular}{lclll}
\hline \multicolumn{1}{c}{ Source } & $\phi$ & $N\left(\mathrm{~s}^{-1}\right)$ & Fuel & $r_{\mathrm{f}}(\mathrm{mm})$ \\
\hline Shen et al. [60] & & & & \\
$\quad$ Case 1 & 1.0 & 1500 & Indolene & 3.2 \\
Case 2 & 1.3 & 1500 & Indolene & 3.2 \\
Case 3 & 1.4 & 1500 & Indolene & 3.2 \\
Boulouchos et al. [61] & & & & \\
$\quad$ Case 1 & 1.0 & 1500 & Propane & 2.25 \\
$\quad$ Case 2 & 0.7 & 1500 & Propane & 1.25 \\
Case 3 & 1.0 & 3000 & Propane & 1.50 \\
Harweg and Maly [55] & & & & \\
TCI (cent) & 1.0 & $300 \rightarrow 1250$ & Propane & $2.8 \rightarrow 3.7$ \\
TCI (per) & 1.0 & $300 \rightarrow 1250$ & Propane & $2.8 \rightarrow 4.9$ \\
CDI (cent) & 1.0 & $300 \rightarrow 1250$ & Propane & $2.8 \rightarrow 3.5$ \\
CDI (per) & 1.0 & $300 \rightarrow 1250$ & Propane & $2.8 \rightarrow 4.6$ \\
\hline
\end{tabular}
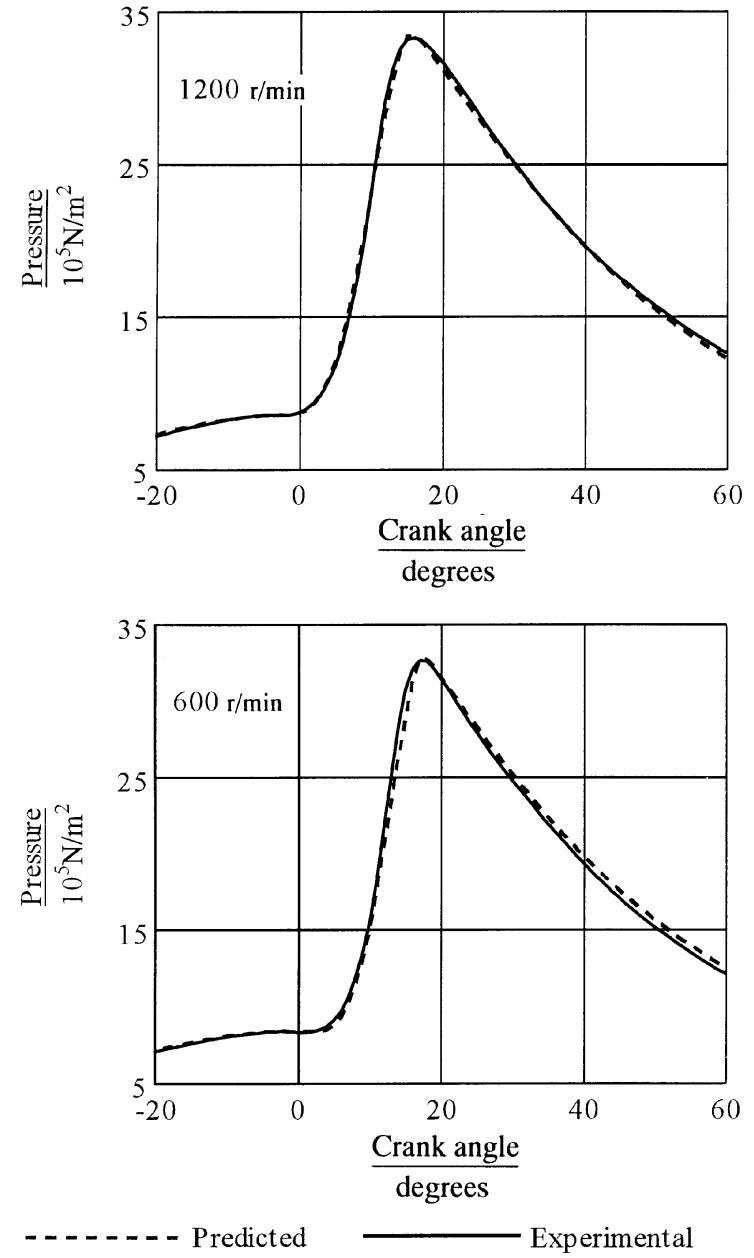

Fig. 6 Predicted and measured [13] pressure-crank angle diagrams for two engine speeds

optical access research engine [13] for engine speeds of 600 and $1200 \mathrm{r} / \mathrm{min}$. Good agreement is obtained at both engine speeds. The engine build and specification are almost identical to those given in Table 1 and the empirical input required for the simulations is summarized in Table 4. It can be seen from the comparison of Tables 2 and 4 that the terms for 'turbulence generation' used in the fired simulations are identical to those used in the motored cases at the same engine speeds. Witze et al. [63] measured the turbulence intensities during motored engine operation at $300 \mathrm{r} / \mathrm{min}$ and compared them with turbulence intensities

Table 4 Operating conditions and empirical input for simulations of measured pressure-crank angle diagrams [13]

\begin{tabular}{lll}
\hline Plug position & Central & Central \\
Engine speed (r/min) & 600 & 1200 \\
Ignition time (CAD) & 357 & 353 \\
Residual mass fraction & 0.02 & 0.01 \\
Turbulence generation & 3.75 & 4.75 \\
Delay period (CAD) & 4 & 5 \\
Temperature at IVC $(\mathrm{K})$ & 345 & 353 \\
Pressure at IVC (bar) & 1.235 & 1.265 \\
Offset $(\mathrm{cm})$ & 0.8 & 0.95 \\
\hline
\end{tabular}

D04097 C) IMechE 1998 
measured in the end-gas under fired conditions in the same engine at the same crank speed. They noted no appreciable differences until 3 CAD before flame arrival at the measurement location. At this point the turbulence intensity measured in the fired engine showed a slight increase. In light of this, and in the absence of data pertaining to the turbulence in the end-gas under fired conditions for the engine speeds simulated here, it is reasonable to assume that any discrepancies between the simulated turbulence field for the motored cases (for which validation is provided in Fig. 5) and the end-gas in the fired case will have little influence on the results.

Figure 7 compares a predicted pressure-crank angle diagram with pressure measurements made by Lucht et al. [11] during the expansion stroke at instants in the engine cycle where thermal boundary layer temperature measurements were made. The engine was similar to that used by Witze et al. [13]. Table 5 summarizes the empirical input used for this simulation. The inlet temperature and pressure are both greater than those used in the simulations of the pressure-crank angle data from [13] because the inlet charge was heated to $373 \mathrm{~K}$ and compressed to $1.27 \mathrm{~atm}$ before induction. Also, the compression ratio was increased to 7.1 by the use of a cylinder head modified to enable very close optical access at the gas/wall interface. It was necessary to adjust the empirical constant for turbulence

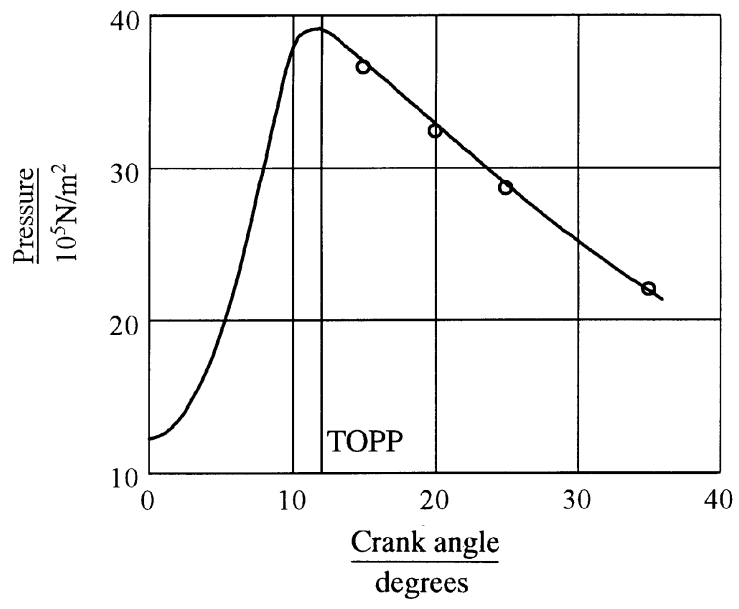

Fig. 7 Predicted pressure-crank angle diagram and pressures measured during the expansion stroke [11]

Table 5 Operating conditions and empirical input for simulations of measured near-wall temperatures [11]

\begin{tabular}{ll}
\hline Plug position & Central \\
Engine speed (r/min) & 600 \\
Ignition time (CAD) & 355 \\
Residual mass fraction & 0.02 \\
Turbulence generation & 4.0 \\
Delay period (CAD) & 3 \\
Temperature at IVC $(\mathrm{K})$ & 450 \\
Pressure at IVC $(\mathrm{bar})$ & 1.465 \\
Offset $(\mathrm{cm})$ & 0.8 \\
\hline
\end{tabular}

generation and reduce the ignition delay from the values used in the previous simulation of the $600 \mathrm{r} / \mathrm{min}$ case. It is proposed that this is likely to be due to slightly higher turbulence intensities produced with this engine build owing to the higher compression ratio. The predicted time of peak pressure (TOPP) is within 1 CAD of the measured one and good agreement is afforded between the predicted pressure curve and the pressures measured during the expansion stroke. Previous studies $[\mathbf{2 4}, \mathbf{4 4}]$ have validated the techniques adopted here in the prediction of thermal boundary layers in the unburned charge. This has been extended here to considerations of such profiles in the burnt charge.

Predicted thermal boundary layer profiles in the burnt gas are compared in Fig. 8 with those measured at a point on the cylinder head $1.905 \mathrm{~cm}$ from the central spark plug. Good predictions of the core temperature (away from the wall) are afforded for the first three cases, but a discrepancy is apparent for the 35 CAD case. This is likely to be a result of errors in the prediction of $\psi$ owing to uncertainties in the applicability of the turbulence model at this point in the cycle because of increasing anisotropy and heterogeneity of the turbulence during the expansion process. However, the thermal boundary layer is predicted to thicken during the expansion stroke in a manner corresponding to the measurements and there is also good correlation between the magnitudes of the burnt gas temperatures in the thermal boundary layer. Each temperature measurement is made as an ensemble average of measurements over many consecutive cycles. The accuracy of the prediction of the pressure-crank angle diagrams during the compression stroke (see Fig. 7) coupled with the corresponding thermal boundary layer profiles lends credence to the claim that a phenomenological model of this detailed type is going some way towards enhancing the accuracy of such models with the implications that may ensue for more precise $\mathrm{NO}$ and unburned hydrocarbon emission predictions.

\section{CONCLUSIONS}

A quasi-dimensional engine cycle model has been successfully coupled with a one-dimensional, control volume mesh for the solution of a discretized form of the conservation of enthalpy equation in the near-wall region of a spark ignition engine. This has enabled the thermal boundary layers to be accurately predicted in both the burnt and unburned charge. A $k-\varepsilon$ turbulence model simulating the essential features of the in-cylinder flow has been included and has been shown to give reasonable results. Parameters accounting for the turbulent eddy transport of momentum and enthalpy are computed from the conserved turbulence properties. When these values are used as input to a FFM and the near-wall conservation of enthalpy equation, the model is capable of accurately predicting pressure-crank angle diagrams and near-wall temperature profiles. 

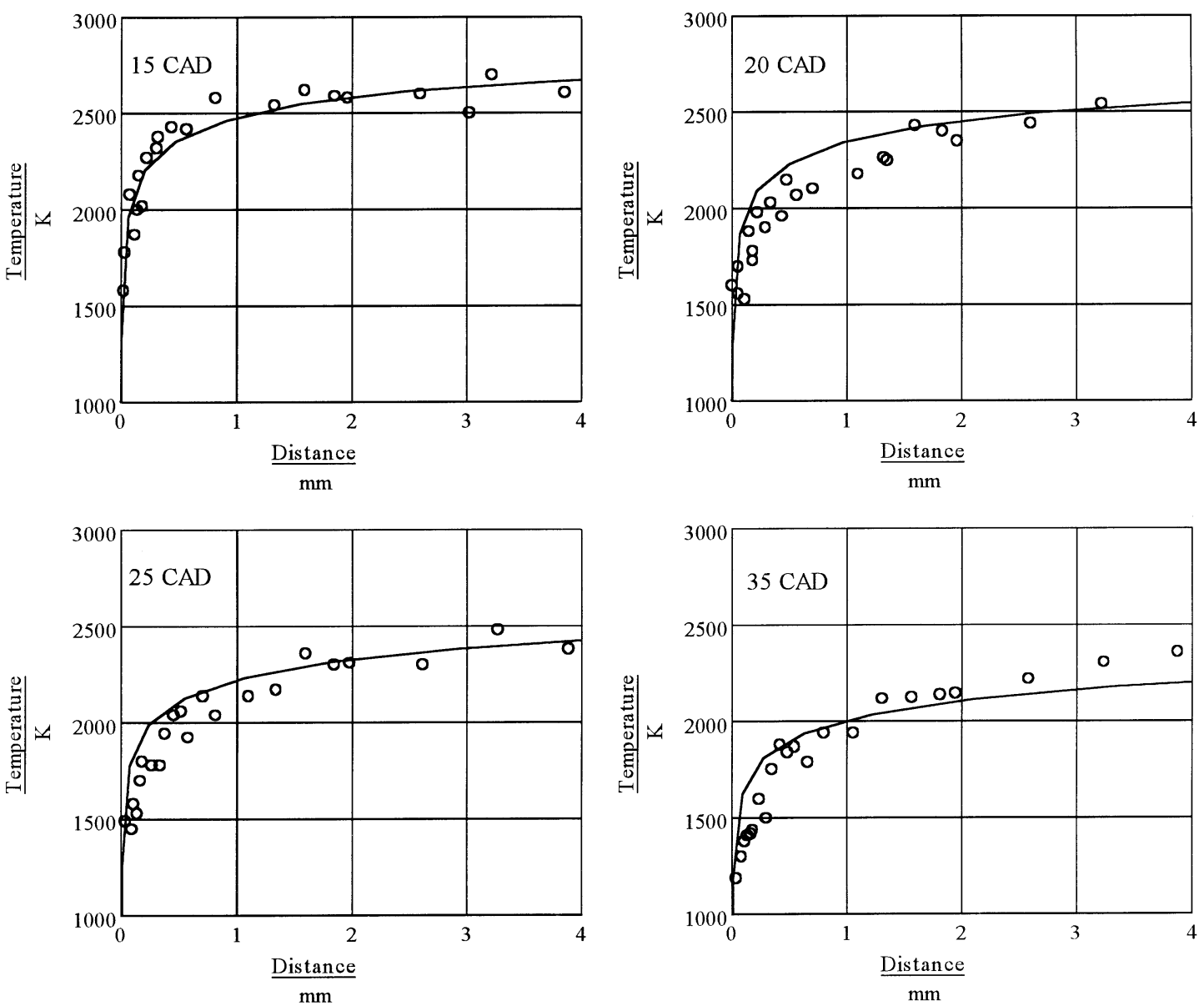

Fig. 8 Measured [11] and predicted burned gas near-wall temperature profiles at four crank angle positions

The model offers considerable improvements in predictive capabilities and accuracy, as demonstrated by the validation shown here. Most significantly, the in-cylinder temperatures and corresponding pressures at points in the cycle have both been accurately accounted for, providing thorough validation for the prediction of the gas state rather than its pressure or temperature alone.

At this stage of development, the model is able to provide much useful information regarding the characteristics of the near-wall temperature field beyond that which can be measured or economically simulated using alternative methods. Such information will be useful for the investigation of the phenomena responsible for abnormal combustion and emissions.

\section{REFERENCES}

1 Chun, K. M. and Heywood, J. B. Estimating heat-release and mass-of-mixture burned from spark-ignition engine pressure data. Combust. Sci. Technol., 1987, 54, 133-143.

2 Foster, D. E. An overview of zero-dimensional thermodynamic models for IC engine data analysis. SAE paper 852070, 1985.
3 Griffiths, J. F., Halford-Maw, P. A. and Rose, D. J. Fundamental features of hydrocarbon auto-ignition in a rapid compression machine. Combust. and Flame, 1993, 95, 291306.

4 Konig, G. and Sheppard, C. G. W. End gas auto-ignition and knock in a spark ignition engine. SAE paper 902135, 1990.

5 Konig, G., Maly, R. R., Bradley, D., Lau, A. K. C. and Sheppard, C. G. W. Role of exothermic centres on knock damage. SAE paper 902136, 1990.

6 Stiebels, B., Schreiber, M. and Sadat Sakak, A. Development of a new measurement technique for the investigation of endgas auto-ignition and engine knock. SAE paper 960827, 1996.

7 Cheng, W. K., Hamrin, D., Heywood, J. B., Hochgreb, S., Min, K. and Norris, M. An overview of hydrocarbon emissions mechanisms in spark-ignition engines. SAE paper 932708, 1993.

8 Norris, M. G. and Hochgreb, S. Extent of oxidation of hydrocarbons desorbing from the lubricant oil layer in sparkignition engines. SAE paper 960069, 1996.

9 Tamura, T. and Hochgreb, S. Chemical kinetic modelling of the oxidation of unburned hydrocarbons. SAE paper 922235 , 1992.

10 Lydford-Pike, E. J. and Heywood, J. B. Thermal boundary layer thicknesses in the cylinder of a spark-ignition engine. Int. J. Heat and Mass Transfer, 1984, 27(10), 1873-1984.

11 Lucht, R. P., Walter, T., Dreier, T., Dunn-Rankin, D. and 
Bopp, S. C. Heat transfer in engines: comparison of CARS thermal boundary layer measurements and heat flux measurements. SAE paper 910722, 1991.

12 Farrell, P. V. and Verhoeven, D. D. Heat transfer measurements in a motored engine using speckle interferometry. SAE paper 870456, 1987.

13 Witze, P. O., Martin, J. K. and Borgnakke, C. Measurements and predictions of the precombustion fluid motion and combustion rates in a spark ignition engine. Trans. Soc. Automot. Engrs, 1983, 92, 786-796.

14 Jennings, M. J. and Morel, T. An improved near wall heat transfer model for multidimensional engine flow calculations. SAE paper 900251, 1990.

15 Jennings, M. J. and Morel, T. A computational study of wall temperature effects on engine heat transfer. SAE paper 910459, 1991

16 Hall, M. J. and Bracco, F. V. Cycle-resolved velocity and turbulence measurements near the cylinder wall of a firing S.I. engine. SAE paper 861530, 1986.

17 Launder, B. E. and Spalding, D. B. Lectures in Mathematical Models in Turbulence, 1972 (Academic Press, London).

18 Pan, J. and Sheppard, C. G. W. A theoretical and experimental study of the modes of end gas auto-ignition leading to knock in S.I. engines. Trans. Soc. Automot. Engrs, 1994, 103, Sec. 4, 1925-1947.

19 Min, K. and Cheng, W. K. In-cylinder oxidation of pistoncrevice hydrocarbon in SI engines. In Proceedings of 3rd International Symposium on The Diagnostics and Modelling of Combustion in Internal Combustion Engines, Yokohama, Japan, 1994, pp. 125-130.

20 Lavoie, G. A. and Blumberg, P. N. A fundamental model for predicting fuel consumption, $\mathrm{NO}_{x}$ and $\mathrm{HC}$ emissions of the conventional spark-ignited engine. Combust. Sci. Technol., 1980, 21

21 Versteeg, H. K. and Malalasekera, W. An Introduction to Computational Fluid Dynamics, 1995 (Longman Scientific and Technical, Essex).

22 James, E. H. Temperature gradients in spark ignition engine combustion chambers. SAE paper 800458, 1980.

23 James, E. H. Further aspects of combustion modelling in spark ignition engines. SAE paper 900684, 1990.

24 Jenkin, R. J., James, E. H. and Malalasekera, W. M. Modelling near-wall temperature gradients in 'motored' spark ignition engines. SAE paper 960070, 1996.

25 Phillips, R. A. and Orman, P. L. Simulation of combustion in a gasoline engine using a computer. In Advances in Automobile Engineering, 1996, Part 4 (Pergamon Press, Oxford, New York).

26 Lancaster, D. R., Krieger, R. B., Sorensen, S. C. and Hull, W. L. Effects of turbulence on spark-ignition engine combustion. SAE paper 760160, 1976.

27 Rask, R. B. Laser Doppler anemometer measurements in an internal combustion engine. SAE paper 790094, 1979.

28 Saxena, V. and Rask, R. B. Influence of inlet flows on the flow field in an engine. SAE paper 870369, 1987.

29 Daneshyar, H. and Fuller, D. E. Definition and measurement of turbulence parameters in reciprocating I.C. engines. SAE paper 861529, 1986.

30 Liou, T.-M., Hall, M., Santavicca, D. A. and Bracco, F. V. Laser Doppler velocimetry measurements in valved and ported engines. SAE paper 840375,1984

31 Liou, T.-M. and Santavicca, D. A. Cycle resolved turbulence measurements in a ported engine with and without swirl. SAE paper 830419, 1983.

32 Arcoumanis, C., Bae, C. S. and Hu, Z. Flow and combustion in a four-valve, spark-ignition optical engine. SAE paper 940475, 1994.

33 Arcoumanis, C., Hu, Z., Vafidis, C. and Whitelaw, J. H. Tumbling motion: a mechanism for turbulence enhancement in spark-ignition engines. SAE paper 900060, 1990.

34 Haddaed, O. and Denbratt, I. Turbulence characteristics of tumbling air motion in four-valve S.I. engines and their correlation with combustion parameters. SAE paper 910478, 1991.

35 Davis, G. C. and Borgnakke, C. The effect of in-cylinder flow processes (swirl, squish and turbulence intensity) on engine efficiency-model predictions. SAE paper 820045, 1982.

36 Puzinauskas, P. and Borgnakke, C. Evaluation and improvement of an unsteady heat transfer model for spark ignition engines. SAE paper 910298, 1991.

37 Morel, T., Rackmal, C. I., Keribasr, R. and Jennings, M. J. Model for unsteady heat transfer and combustion in spark ignited engines and its comparison with experiments. SAE paper $880198,1988$.

38 Borgnakke, C., Davis, G. C. and Tabaczynski, R. J. Predictions of in-cylinder swirl velocity and turbulence intensity for an open chamber cup in piston engine. SAE paper 810224, 1981.

39 Hall, M. J. and Bracco, F. V. A study of velocities and turbulence intensities measured in firing and motored engines. SAE paper 870453, 1987.

40 Arcoumanis, C. A., Bicen, A. F. and Whitelaw, J. H. Effect of inlet flow parameters on the flow characteristics in a fourstroke model engine. SAE paper 820750, 1982.

41 Pierce, P. H., Ghandi, J. B. and Martin, J. K. Near-wall velocity characteristics in valved and ported engines. SAE paper 920152, 1992

42 Foster, D. E. and Witze, P. O. Velocity measurements in the wall boundary layer of a spark ignited research engine. SAE paper 872105, 1987.

43 Heywood, J. B. Fluid motion within the cylinder of internal combustion engines - the 1986 Freeman Scholar Lecture. Trans. ASME, J. Fluids, 1987, 109, 3-35.

44 Jenkin, R. J., James, E. H. and Malalasekera, W. Thermal boundary layer modelling in 'motored' spark ignition engines. SAE paper 961965, 1996.

45 Mantzaras, J. Geometrical properties of turbulent premixed flames: comparison between computed and measured quantities. Combust. Sci. Technol., 1992, 86, 135-162.

46 Gouldin, F. C. An application of fractals to modelling premixed turbulent flames. Combust. and Flame, 1987, 68, 249-266.

47 Metghalchi, M. and Keck, J. C. Burning velocities of mixtures of air with methanol, iso-octane and indoline at high pressure and temperature. Combust. and Flame, 1982, 48.

48 North, G. L. and Santavicca, D. A. The fractal nature of premixed turbulent flames. Combust. Sci. Technol., 1990, 72, 215-232.

49 Chin, Y.-W., Matthews, R. P., Nichols, S. P. and Kiehne, T. M. Use of fractal geometry to model turbulent combustion in SI engines. Combust. Sci. Technol., 1992, 86, 1-30.

50 Murayama, M. and Takeno, T. Fractal like character of flamelets in turbulent premixed combustion. In Proceedings of 
22nd International Symposium on Combustion, 1990, pp. 551-559 (The Combustion Institute).

51 Gouldin, F. C., Hilton, S. M. and Lamb, T. Experimental evaluation of the fractal geometry of flamelets. In Proceedings of 22nd International Symposium on Combustion, 1990, pp. 541-550 (The Combustion Institute).

52 Zhao, X., Matthews, R. D. and Ellzey, J. L. Numerical simulations of combustion in SI engines: comparison of the fractal flame model and the coherent flame model. In Proceedings of 3rd International Symposium on The Diagnostics and Modelling of Combustion in Internal Combustion Engines, Yokohama, Japan, 1994, pp. 157-162.

53 Mantzaras, J., Felton, P. G. and Bracco, F. V. Threedimensional visualization of premixed-charge engine flames: islands of reactants and products; fractal dimensions; and homogeneity. SAE paper 881635, 1988.

54 Santavicca, D. A., Liou, D. and North, G. L. A fractal model of turbulent flame kernal growth. Trans. Soc. Automot. Engrs, 1990, 99, Sec. 3, 90-98.

55 Harweg, R. and Maly, R. R. A fundamental model for flame kernal formation in S.I. engines. Trans. Soc. Automot. Engrs, 1992, 101, Sec. 3, 1947-1976.

56 Wu, C.-M., Roberts, C. E., Matthews, R. D. and Hall, M. J. Effects of engine speed on combustion in SI engines: comparison of predictions of a fractal burning model with experimental data. Trans. SAE, 1993, 102, Sec. 3, 2277-2291.
57 Witze, P. O. Interpretation of head-gasket ionisation-probe measurements using a two-zone spherical flame model. In Proceedings of 3rd International Symposium on The Diagnostics and Modelling of Combustion in Internal Combustion Engines, Yokohama, Japan, 1994, pp. 453-458.

58 Barr, P. K. and Witze, P. O. Some limitations to the spherical flame assumption used in phenomenological engine models. SAE paper 880129, 1988.

59 Matthews, R. D. and Chin, Y.-W. A fractal based SI engine model: comparisons of predictions with experimental data. Trans. Soc. Automot. Engrs, 1991, 100, Sec. 3, 99-117.

60 Shen, H., Hinze and Heywood, J. B. A model for flame initiation and early development in SI engine and its application to cycle to cycle variations. SAE paper 942049 , 1994.

61 Boulouchos, K., Steiner, T. and Dimopoulos, P. Investigation of flame speed models for the flame growth period during premixed engine combustion. Trans. Soc. Automot. Engrs, 1994, 103, Sec. 4, 212-224.

62 Kumar, S., De-Zylva, M. D. and Watson, H. C. Prediction of cyclically-variable pressure-time history of a S.I. engine using a quasi-dimensional spherical flame front model. SAE paper 912454, 1991.

63 Witze, P. O., Martin, J. K. and Borgnakke, C. Conditionally-sampled velocity and turbulence measurements in a spark ignition engine. Combust. Sci. Technol., 1984, 36, 301-317. 